\title{
Erratum to: Evaluation of an Interdisciplinary Curriculum Teaching Team-Based Care Integration in Oncology
}

\author{
Barbara A. Head ${ }^{1,7}$ - Tara Schapmire ${ }^{1}$ Lori Earnshaw $^{1}$ - Anna Faul ${ }^{2,3}$. \\ Carla Hermann ${ }^{4}$ - Carol Jones ${ }^{1}$ - Amy Martin ${ }^{1}$ - Monica Ann Shaw ${ }^{1}$. \\ Frank Woggon ${ }^{5}$ - Craig Ziegler ${ }^{6}$ - Mark Pfeifer ${ }^{1}$
}

Published online: 6 January 2016

(C) American Association for Cancer Education 2016

Erratum to: J Canc Educ (2015)

DOI 10.1007/s13187-015-0799-y

In the above-mentioned article, the author name Mark Pfeifer was written incorrectly as Mark Pfeiffer. However, this error has been already corrected in both the referenced article and in the author listing for this article.

The online version of the original article can be found at http://dx.doi.org/ 10.1007/s13187-015-0799-y.

Barbara A. Head

barbara.head@louisville.edu

1 Division of General Internal Medicine, Medical Education and Palliative Medicine, University of Louisville School of Medicine,

Louisville, KY 40292, USA

2 University of Louisville Kent School of Social Work, Louisville, KY 40292, USA

3 University of the Free State, Bloemfontain, South Africa

4 University of Louisville School of Nursing, Louisville, KY 40292, USA

5 University Hospital, Louisville, KY 40202, USA

6 Office of Undergraduate Medical Education, University of Louisville School of Medicine, Louisville, KY 40292, USA

7 MedCenter One, Suite 330B 501 East Broadway, Louisville, KY 40202, USA 